The Long Reach of the Leader:

Can Empowering Leadership at Work Result in Enriched Home Lives?

\author{
Minseo Kim $^{1}$ and Terry A. Beehr ${ }^{2}$ \\ ${ }^{1}$ College of Business, Hankuk University of Foreign Studies, Seoul, 02450, South Korea \\ ${ }^{2}$ Department of Psychology, Central Michigan University, Mount Pleasant, Michigan 48859, \\ U.S.A.
}

We presented some of these data at the April 2018 Society for Industrial and Organizational Psychology Annual Meeting in Chicago, Illinois.

\title{
Author biographies
}

Minseo Kim is a PhD student in the Department of Management and Organization Studies at Hankuk University of Foreign Studies, South Korea. Her research interests include occupational stress, leadership, motivation, job crafting, and employee well-being.

Terry A. Beehr is a Professor of Psychology and member of the I/O Psychology faculty at Central Michigan University. His research interests include occupational stress, leadership, motivation, careers, and retirement.

Correspondence should be addressed to Minseo Kim, Department of Management and Organization Studies at Hankuk University of Foreign Studies, Seoul 02450, South Korea. Email:minseokim0331@gmail.com 
WORK TO HOME EFFECT OF EMPOWERING LEADERSHIP 2

The Long Reach of the Leader:

\section{Can Empowering Leadership at Work Result in Enriched Home Lives?}

Keywords: empowering leadership; need satisfaction; work engagement; work-home enrichment 
WORK TO HOME EFFECT OF EMPOWERING LEADERSHIP 3

\begin{abstract}
Work-home enrichment occurs when employees' work roles and experiences lead to benefits and resources that improve the quality of life in the home role. Guided by self-determination theory (SDT), we developed a serial mediation model in which empowering leadership predicted workhome enrichment via satisfaction of innate psychological needs of SDT and then via work engagement. Four-waves of data over a 9-month period were obtained from 289 full-time U.S. employees. Structural equation modeling and the PROCESS macro were used to verify the indirect effect of empowering leadership on work to home enrichment. Empowering leadership predicted subordinates' need satisfaction, which in turn, predicted work engagement. Work engagement was then associated with positive spillover from work to home roles in the form of work-home enrichment. Theoretically, empowering leadership is a condition of the work environment that can satisfy important psychological need requirements outlined in SDT and promote work engagement, thereby influencing employees' home functioning. Integrating the frameworks of empowering leadership and SDT, this study provided valuable insights for general employee well-being by showing how empowering leadership could have a spillover effect in the form of work-home enrichment.
\end{abstract}

Keywords: empowering leadership; need satisfaction; work engagement; work-home enrichment 
WORK TO HOME EFFECT OF EMPOWERING LEADERSHIP 4

\section{The Long Reach of the Leader:}

\section{Can Empowering Leadership at Work Result in Enriched Home Lives?}

Empowering leadership consists of leader behaviors that include delegating, encouraging subordinates' responsibility for self-leadership, increasing authority and autonomy, promoting participative decision making, and providing support for subordinates' development by modeling and coaching (Amundsen \& Martinsen, 2014; Zhang \& Bartol, 2010). Taken together, this set of behaviors is an indicator of a global leadership construct that is associated with favorable subordinates' reactions, because for most employees it leads to satisfying job characteristics that can generate intrinsic motivation, consistent with traditional job enrichment variables, such as autonomy and variety (e.g., Hackman \& Oldham, 1980). Two recent meta-analyses reported positive relationships between overall empowering leadership and work-related outcomes, such as work motivation, performance, creativity, and work attitudes (Kim, Beehr, \& Prewett, 2018;

Lee, Willis, \& Tian, 2018). The present study examines the potential for empowering leadership to favorably influence the work-to-home interface, an important issue in workers' overall wellbeing. Research often labels this interface as the work-family interface, but it is more generally the work-home interface, especially for employees who may not be living with or interacting frequently with family members. Additionally, the label "home" instead of the family encompasses employees' various life roles outside of work and not just the family role (ten Brummelhuis \& Bakker, 2012).

Leader behaviors can have secondary effects that go beyond the work boundary (Li, McCauley, \& Shaffer, 2017). Much research on such work-to-home spillover has focused on the negative issue of work-family conflict (Allen \& Martin, 2017), which can lead to poorer wellbeing for the employee. We argue that self-determination theory (SDT; Deci \& Ryan, 2000) can 
WORK TO HOME EFFECT OF EMPOWERING LEADERSHIP 5

help explain how the more positive spillover effects of work-home enrichment can occur. If type of leadership can affect employees' nonwork lives, there is a chance it can have positive spillover effects into the home life. Such positive spillover has been labelled work-home enrichment, and it can result in multiple favorable effects on the employee and his or her family (e.g., a meta-analysis by Zhang, Xu, Jin, \& Ford, 2018).

In order to explain this spillover more completely, the present study therefore integrates the empowering leadership and self-determination theory literatures to examine the processes through which empowering leadership predicts employee work-home enrichment. By considering SDT theory's set of employee's innate psychological need satisfactions and work engagement as explanatory mechanisms, the present study is the first examination providing evidence for why empowering leadership is an important resource with potential influence beyond the workplace. We develop a model explaining why empowering leadership can facilitate employees' work-home enrichment. In so doing, the study also shows spillover in which positive work-related experiences (beginning with empowering leadership and potentially mediated by both critical need satisfactions and work engagement) can result in enriched home lives.

Leaders may have the ability to generally affect employees' nonwork lives (e.g., Braun \& Nieberle, 2017), and empowering leadership is a particularly strong type of leadership, involving both delegation of authority and employee development, as well as encouragement by expressing confidence in subordinates. Subordinates of empowering leaders can be developed and molded into more competent and confident people, which may result in being more effective in all parts of their lives, their home lives, as well as their work lives. We already know that generally favorable experiences from one life domain (e.g., the work role) can be related to the quality of 
WORK TO HOME EFFECT OF EMPOWERING LEADERSHIP 6

experiences in another life domain (e.g., the home role) (Greenhaus \& Powell, 2006), and empowering leadership is strong enough to have such positive spillover effects from the work role to the home role. We explain this relationship by proposing two sequential mediators, subordinates' satisfaction of SDT needs and their work engagement (model in Figure 1, which also contains the results).

The first link in the model is from empowering leadership to satisfaction of subordinates' self-determination needs. Self-determination theory (SDT) proposes that individuals have a set of innate self-determination needs: needs for autonomy, competence, and relatedness. The satisfaction of all of these psychological needs is essential for individuals' motivation, optimal functioning, and well-being (Deci \& Ryan, 2000; Ryan \& Deci, 2000). Autonomy is necessary for employees to feel responsible for their work, feelings of competence are necessary for employees to believe they can succeed if they try, and relatedness to others is centrally important for the person to internalize their motivation (e.g., Ryan \& Deci, 2000). Therefore, all of these elements of SDT theory are necessary, and they empirically form a single global construct (e.g., Huyghebaert, Gillet, Fernet, Lahiani, Chevalier, \& Fouqueraou, 2018); thus we study them as the single variable, needs satisfaction. In the workplace, satisfaction of these employee needs is theorized to result from crafting job characteristics to improve person-environment fit, among other things (Greguras \& Diefendorff, 2009; Van den Broek, Vansteenkiste, De Witte, \& Lens, 2008; Van Wingerden, Bakker, \& Derks, 2017). Leaders can be particularly salient to such proactive, self-controlled subordinate actions.

We chose to study empowering leadership because it is focused on encouraging the subordinate to take responsibility for his or her own work and outcomes, specifically including the leader behaviors of encouraging independent action, encouraging opportunity thinking, 
encouraging teamwork, encouraging self-development, participative goal setting, and encouraging self-reward (Pearce \& Sims, 2002). These leadership behaviors are based on participative management and self-management theories, and they fit very well with the need satisfactions from self-determination theory, the first link in the model. Other leadership styles might have some effect on the satisfaction of SDT's autonomy, competence, and relational needs, but they are not as focused on and consistent with them. The popular transformational leadership style, for example, is broader, encompassing the leader behaviors of providing vision, expressing idealism, using inspirational communication, and having high performance expectation; it is based in part on charismatic theory (Pearce \& Sims, 2002). Both of these leadership styles are advocated for enhancing certain "standard" outcomes in the organizational sciences, such as task performance, organizational citizenship behaviors, and reducing turnover, but empowering leadership better explains the satisfaction of SDT needs. Thus, although there may be some commonalities, they are also noticeably different conceptually. Empirically, Tekleab, Sims, Yun, Tesluk, and Cox (2008) also showed empowering leadership and transformational leadership were empirically differentiated in a confirmatory factor analysis.

Although SDT is supported by research in a variety of domains and has been theorized to influence important work outcomes, it has gained little attention in leadership research. In organizational contexts, leaders can play important roles for psychological need fulfillment of subordinates, and we argue that employees' psychological needs based on SDT will be satisfied by empowering leader behaviors because of their focus on promoting subordinates' autonomous work motivation, joint decision-making, and support for professional development (Kim \& Beehr, 2019). Empowering leadership should result in satisfaction of SDT theory needs. It directly entails providing autonomy to subordinates through its delegation of authority, it 
WORK TO HOME EFFECT OF EMPOWERING LEADERSHIP 8

supports and encourages feelings of competence by providing developmental support and expressions of confidence, and it encourages feelings of relatedness to the leader (as evidenced by its strong meta-analytic correlation with leader-member relations; Kim et al., 2018).

Hypothesis 1: Empowering leadership is positively related to subordinates' need satisfaction.

We propose, consistent with SDT, that employee development based on these organizational experiences constitutes the general development of the person as a human being, and such development can eventually extend beyond the workplace. The second step in the model is a link between need satisfaction and work engagement as a second sequential mediator in the overall link between empowering leadership and work-home enrichment. Work engagement is an overall positive, affective-motivational psychological state characterized by vigor, dedication, and absorption (Xanthopoulou, Bakker, Demerouti, \& Schaufeli, 2009). As an overall construct, engagement hangs together as a unified whole. It is employees' positive, fulfilling states of mind in connection to their work, in which they are engrossed in their work, focused on their work, and can often express their "selves" through their work (Inceoglu \& Fleck, 2010; Schaufeli, Bakker, \& Salanova, 2006). Empirically, although CFAs often support three factors, one-factor models also fit well, and the correlations between the latent factors of the subscales can be greater than .90, suggesting a single overall construct (Schaufeli et al., 2006).

Because the empowering leader helps to satisfy the employee's SDT needs during their development, the employee becomes more engaged in the work. When employees experience autonomy, and feelings of competence and relatedness, this suggests that the organization values and trusts them to do well. This is an implicit form of encouragement for employees to feel 
WORK TO HOME EFFECT OF EMPOWERING LEADERSHIP 9

confident and engaged in their work. Thus, the need satisfaction following leaders' treatment of subordinates may result in subordinates' work engagement.

Hypothesis 2: Employees' need satisfaction is positively related to their work engagement.

Work engagement is expected to produce a positive effect in the form of increased energy and psychological resources, including optimism and self-efficacy (Xanthopoulou et al., 2009), further enhancing employees' self-assurance and competence. We propose that these employee characteristics can transfer to their home domains, resulting in work-home enrichment, that is, the degree to which work experiences improve the quality of life and performance of the employee in the home role (Greenhaus \& Powell, 2006). An example would be responsibilities given to employees through empowering leadership improve their confidence and decisionmaking abilities enough to enhance performance in their home roles when they need to take responsibility and make decisions there. Therefore, positive work-to-home spillover can occur when favorable psychological states in the workplace continue after the employee goes home (Greenhaus \& Powell, 2006; Grzywacz \& Marks, 2000).

Hypothesis 3: Employees' work engagement is positively related to their experience of work-family enrichment.

In addition to testing the overall model, we further hypothesized and tested subhypotheses about separate mediations that are inherent in the model. First, need satisfaction is expected to mediate the relationship of empowering leadership with employees' engagement. Although this has not been tested before, one previous study reported empowering leadership was related to employee engagement via work meaningfulness (Lee, Idris, \& Delfabbro, 2017) and psychological capital (Park, Kim, Yoon, \& Joo, 2017). We propose, however, that with their 
leader behaviors, empowering leaders are likely to fulfill subordinates' psychological need based on SDT theory (Deci \& Ryan, 2000). This is because empowering leaders directly place emphasis on employees' autonomy and encourage them to develop self-leadership and confidence for exercising decision-making in their jobs, often making decisions with other people through participative decision-making (Kim \& Beehr, 2019). These features of empowering leadership match up well with the set of SDT needs for autonomy, competence, and relatedness.

Empowering leadership should satisfy SDT needs in multiple ways. It offers personal and professional challenges with high standards while simultaneously expressing confidence in subordinates' abilities, and also the leader is willing to provide development support for the subordinate through coaching, consulting, and modeling (Kim \& Beehr, 2018). These behaviors of the empowering leader can make subordinates feel capable and effective. Empowering leaders seek subordinates' ideas and opinions, helping to promote collaboration through sharing information (Arnold, Arad, Rhoades, \& Drasgow, 2000), which should result in positive communication and interactions among employees, increasing their sense of belongingness. A participative goal-setting process and encouragement of taking initiative also increase subordinates' experiences of self-control.

SDT need satisfaction helps transmit the effects of empowering leaders to employees' engagement in their work; the theory suggests that most employees need to feel autonomous, competent, and belonging in order to experience the control, commitment, and enthusiasm of work engagement (Deci \& Ryan, 2000). In line with this argument, prior research found a positive link between fulfillment of psychological needs and overall work engagement (Schreurs, van Emmerik, Van den Broeck, \& Guenter, 2014) and also with one specific element of 
engagement, vigor (Van den Broek et al., 2008). The first two links in the model propose that empowering leadership helps satisfy important needs of subordinates and that this psychological need satisfaction can enhance their engagement. Thus, we posit that empowering leadership may have its effects on engagement because it satisfies employees' innate needs.

Hypothesis4. Satisfaction of employees' innate psychological needs mediates the relationship between empowering leadership and their experience of engagement. We also propose that there will be a potential spillover effect of a positive work-related state (engagement) on employees' home roles, resulting in work-home enrichment and that this effect completes the explanation for how empowering leadership at work can enrich employees' non-work lives. Work-home enrichment arises when work experiences improve the quality of home life; Greenhaus and Powell's (2006) model of work-family enrichment suggests that skills and various types of resources generated from participation in role A (here, the work role) result in high performance and positive affect in role B (here, the home role). The model in Figure 1 proposes that engagement can mediate the relationship between employees' need satisfaction and their work-home enrichment. Highly engaged employees experience high levels of energy and enthusiasm, being fully immersed in their jobs (Xanthopoulou et al., 2009). Through a spillover process (Greenhaus \& Powell, 2006; Grzywacz \& Marks, 2000), that energy and positive attitude can have a favorable influence on (i.e., can enrich) the employee's home life.

We therefore expect that engagement may have positive outcomes for the home role. Additionally, positive affect experienced in one role (work) may increase self-efficacy, motivation, and positive interpersonal interactions in another role, resulting in more effectiveness in the other role (home), the essence of the spillover construct (Greenhaus \& Powell, 2006; Grzywacz \& Marks, 2000). Subsequently, improved effectiveness leads to recognition or praise 
from role partners or feelings of personal accomplishment, which positively affects family relationships and family affective states, according to causal models of spillover between work and family (Edwards \& Rothbard, 2000). Because work and family roles involve expectations about affective expressions (Rafaeli \& Sutton, 1987), feelings experienced in the organizational context can influence family functioning by affecting a person's general affect as well (Cho \& Tay, 2016; Edwards \& Rothbard, 2000). Taken together, the elements of engagement gained from need satisfaction capture the nature of the positive role experiences and psychological states at work. Therefore, they should be beneficial to the employees in terms of facilitating family responsibilities by promoting work-home enrichment, and they explain the transfer of needs satisfaction effects at work to life outside the workplace.

Hypothesis 5. Work engagement mediates the relationship between employees' needs satisfaction and their work-to-home enrichment.

As explained above, the model in Figure 1 proposes serial mediation from empowering leadership to subordinates' needs satisfaction, to engagement in their work, and ultimately spilling over to the non-work domain in the form of work-to-home enrichment. Mediation is the key issue in the model, and our main hypothesis concerns testing the overall model.

Hypothesis 6. Empowering leadership is related to employees' work-to-home enrichment through serial mediation by their needs satisfaction and work engagement.

In summary, the present study explains why empowering leadership should have a positive effect on work-home enrichment, proposing a serial mediating model in which empowering leadership first results in subordinates' needs satisfaction, which in turn results in their work engagement and subsequently in work-home enrichment. We propose and test the 
WORK TO HOME EFFECT OF EMPOWERING LEADERSHIP 13

overall model explaining why empowering leadership can lead to work-home enrichment (Hypothesis 6), as well as testing its two sub-parts (Hypotheses 4 and 5) for mediation.

\section{Method}

\section{Participants and Procedure}

Participants were full-time employees in the United States, working in a variety of industries (e.g., education, health care, and finance); they were recruited through Amazon's Mechanical Turk (MTurk), a commercial service that pays respondents for participating in surveys and that provides research participants from a broad range of jobs, people, and geographic locations. MTurk has been a research base since 2005, and accumulated methodological studies have now shown that MTurk from employees in U.S. organizations provides high-quality research data. That is, they tend to read survey's instructions carefully and to be moderately representative of the U.S. population (e.g., Ramsey, Thompson, McKenzie, \& Rosenbaum, 2016). A recent meta-analysis confirmed its reliability and criterion-related validity; reliabilities and effect sizes for variables commonly used in organizational behavior and human resource management research are similar for online data platforms (including MTurk) and other types of employee samples (Walter, Seibert, Goering, \& O’Boyle, 2018). Overall, recent empirical studies and methodological reviews concluded that MTurk data are comparable to other data sources commonly used in organizational research (Keith, Tay, \& Harms, 2017). Consistent with best-practices recommendations, we invited only full-time U.S. employees holding at least a 95\% approval rating from previous MTurk assignments; these participants tend to be especially conscientious and provide highly reliable responses with low social desirability effects (Casler, Bickel, \& Hackett, 2013). The total amount of money participants received for participating in all four phases of the study was $\$ 4.00$. 
Leadership behaviors may have time-lagged effects on changes in work-home relationships. Furthermore, previous studies on work-home interfaces adopted approximately six-month time lags between the measurement of work-related resources and work-home enrichment to allow sufficient fluctuation over time (Matthews, Wayne, \& Ford, 2014; Russo, Buonocore, Carmeli, \& Guo, 2018). Thus, we collected data at four points in time over nine months; there were one-month time lags between the first and second measurements and between the second and third measurements, with a time lag of seven months between the third and fourth measurements (of work engagement and work-home enrichment, to allow examining the medium-term lagged effect). In using a longer time lag for the final link in the model, we reasoned that the effects of a work-related variable on other variables in the workplace would occur more quickly, and it would take a longer time period for effects of workplace variables to spill over to affect the employee's home life. Additionally, measuring each variable at different points in time helps reduce common method bias effects (Podsakoff, MacKenzie, \& Podsakoff, 2012). We also employed standard data-analytic quality-control procedures (Cheung, Burns, Sinclair, \& Sliter, 2017). As recommended, first, we included reverse-worded and attentioncheck screening items to identify and eliminate non-purposeful responses. Second, data from participants with apparent low effortful responding were eliminated: data with too many of the same responses $(80 \%)$ or from people who completed the survey four times faster than the mean. Finally, multivariate outliers were removed.

Initially, 700 employees answered the time 1 survey. We eliminated 58 cases due to disqualification for the study's sample requirements (e.g., Non-US full-time employees) and 16 cases due to only partially completing surveys (greater than $50 \%$ missing data). We then excluded 22 non-purposeful and low-effort responses, resulting in usable data for 604 
respondents to the first survey. An invitation email was sent to these 604 participants for followup surveys, and 543 responded to the time 2 survey and 382 to the time 3 survey. After dropping 24 cases with low-effort responding and failed attention checks, we invited 358 participants to the fourth survey. Among them, 292 completed the time 4 survey; three responses were deleted due to extreme outliers. Thus, in the final sample, hypotheses were tested with 289 respondents, representing a retention rate of $47.8 \%$ for four waves of data collections over a nine-month time period. In the final sample, there were $55.4 \%$ men, $80.1 \%$ Caucasians, and $68.4 \%$ with a bachelor's degree or more education. Their average age was 36.0 years $(S D=9.69)$, and $40.8 \%$ was single, $52.9 \%$ married, $6.2 \%$ divorced, and $0.1 \%$ others (e.g., cohabit). Participants worked on average 40.65 hours $(S D=7.75)$ per week and had been employed in their current organization for about seven years $(S D=6.99)$. In this sample, $59.9 \%$ were line employees, $17.6 \%$ were low-level supervisors, $15.9 \%$ were managers, and $6.6 \%$ were executives.

\section{Measures}

Study variables were sequentially measured at four time points as illustrated in Figure 1. All measures were chosen from previously published studies, and their reliabilities in the present study are shown in Table 1.

Empowering leadership (T1) was measured at Time 1 using Zhang and Bartol's (2010) 12-item measure $(\alpha=.91)$, which was originally from Ahearne et al (2005). It includes four dimensions: autonomy (e.g., "My supervisor allows me to do my job my way"), meaningfulness of work (e.g., "My supervisor helps me understand the importance of my work to the overall effectiveness of the company"), participation in decision making (e.g., "My supervisor solicits my opinion on decisions that may affect me"), and confidence in high performance (e.g., "My 
supervisor believes that I can handle demanding tasks"), rated on a 5-point Likert scale from 1 (strongly disagree) to 5 (strongly agree).

Needs satisfaction (T2) was assessed at Time 2 using the 16-item $(\alpha=.90)$ WorkRelated Basic Need Satisfaction Scale (W-BNS) from Van den Broeck, Vansteenkiste, Witte, Soenens, and Lens (2010). It includes three dimensions: satisfaction of the autonomy need (e.g., "I feel like I can be myself at my job"), of the belongingness need (e.g., "At work, I feel part of a group"), and of the competency need (e.g., I feel competent at my job), rated on a 5-point Likert scale from 1 (strongly disagree) to 5 (strongly agree).

Work engagement (T3) was measured at Time 3 with the 9-item $(\alpha=.95)$ Utrecht Work Engagement Scale by Schaufeli et al. (2006). Example items are: “At work, I feel bursting with energy" (vigor), "My job inspires me” (dedication), and "I feel happy when I am working intensely" (absorption), rated on a 7-point frequency scale from 1 (never) to 7 (always).

Work-home enrichment (T4) was assessed at Time 4 using the four-item $(\alpha=.91)$ from Grzywacz and Marks (2000). Those researchers referred to the variable as work-family enrichment, but the items are written without reference to family, and so they are appropriate for measuring work-home enrichment among employees more generally. An example item is "Having a good day on your job makes you a better companion when you get home," rated on a 5-point frequency scale from 1 (never) to 5 (all the time).

Potential control variables included sex, age, marital status, and trait affect. Demographics, especially sex and age, have often been associated with variables at the workhome interfaces; depending on gender and stage of life, there may be different implications for work-home considerations (e.g., Grzywacz, Almeida, \& McDonald, 2002). Therefore, we examined sex, age, and marital status in the analyses. However, of these three, only marital status 
was significantly related to any of the variables in Figure 1. It was related only to empowering leadership $(r=.14, p<.05)$ and needs satisfaction $(r=.15, p<.01)$, and so we just controlled for marital status at the first step in the hypothesized model. Controlling for marital status did not affect the path coefficients and conclusions in the present study however, and therefore we omitted the demographic variables from the figure and model testing.

We also controlled for trait affect, with positive and negative affectivity (PA and NA measured at time 3) measured with Positive and Negative Affect Scale (Watson, Clark, \& Tellegen, 1988), which included ten adjectives each about how the person feels (e.g., enthusiastic and irritable) rated on a 5-point scale from 1 (not at all) to 5 (extremely). Positive and negative affectivity were significantly associated with the four study variables except one; the correlation between negative affectivity and work-family enrichment was not significant (see Table 1). Therefore, we included the two forms of trait affect in the model while testing the hypotheses.

\section{Results}

Table 1 shows descriptive statistics, reliabilities, and correlations among the variables. Correlations corresponding to the paths in the hypothesized model are all in the expected direction and significant, supporting Hypotheses 1, 2, and 3. In addition, the corresponding parameters in the model in Figure 1 are all significant, providing additional support for these hypotheses.

\section{Model Testing}

We examined the measurement and hypothesized models with LISREL 8.8 (Jöreskog \& Sörbom, 2006). Empowering leadership's four subscales were used as manifest indicators. Similarly, the three subscales of both need satisfaction and work engagement served as their indicators. The measure of work-home enrichment had a few items and no subscales, and its four 
items were used for indicators. The two control variables, positive and negative affectivity, had ten items each but were also unidimensional constructs without subscales, and thus the itemparceling method was applied (Little, Rhemtulla, Gibson, \& Schoemann, 2013); their items were randomly parceled to create three indicators (two parcels composing of three items and one parcel composing four items). The measurement model (confirmatory factor analysis) without controls fit the data well, $\chi^{2}(71)=125.36, p<.01 ; \mathrm{RMSEA}=.05 ; \mathrm{CFI}=.99 ; \mathrm{IFI}=.99 ; \mathrm{NNFI}=$ 98. The measurement model with controls also showed excellent fit, $\chi^{2}(155)=268.49, p<.01$; RMSEA $=.05 ; \mathrm{CFI}=.98 ; \mathrm{IFI}=.98 ; \mathrm{NNFI}=.98$, justifying the use of global indices of the four variables in the hypothesized model (Figure 1). Table 2 shows the model fit indices.

Starting with the overall hypothesized model (Figure 1) without control variables, it fit the data well, $\chi^{2}(74)=158.94, p<.01 ; \mathrm{RMSEA}=.06 ; \mathrm{CFI}=.98 ; \mathrm{IFI}=.98 ; \mathrm{NNFI}=.97$. The standardized path coefficients are all significant, supporting all links in the model. The overall fit and the path coefficients, therefore, strongly support Hypothesis 6. These results supported a model in which empowering leadership was positively related to subordinates' subsequent needs satisfaction $(\beta=.69, p<.01)$, which in turn was related to subsequent work engagement $(\beta=$ $.50, p<.01$ ), and work engagement showed a significant relationship with later work-home enrichment $(\beta=.29, p<.01)$. The hypothesized model with the two controls (positive and negative affectivity) produced the same fit indices as the one without the controls (Table 2). Thus, even after including positive and negative affectivity in the model, the basic conclusions of the study were not changed, although every path coefficient somewhat decreased: empowering leadership to needs satisfaction from $\beta=.69$ to $\beta=.50$, needs satisfaction to work engagement, $\beta$ $=.50$ to $\beta=.25$, and work engagement to work-home enrichment, $\beta=.29$ to $\beta=.22$. In sum, the 
results suggested that through needs satisfaction and work engagement, empowering leadership can have indirect effects on work-home enrichment.

\section{Alternative Models and Bootstrapping}

Multiple mediation effects are embedded in the model, and to further confirm the mediation effects in a different way, two alternative models were tested with bootstrapping analyses of both direct and indirect effects. Alternative model 1 focused on the criterion variable, work-home enrichment. It added two paths: one from empowering leadership to work-home enrichment, and one from needs satisfaction to work-home enrichment. The additional two direct paths and the overall improvement in fit, $\Delta \chi^{2}(2)=2.47, p=.29$, were not significant, indicating that needs satisfaction and work engagement were indeed important mediators between empowering leadership and work-home enrichment, supporting Hypothesis 6. Alternative model 1 also specifically supported Hypothesis 5, as the direct path from needs satisfaction to workhome enrichment (where only an indirect path had been hypothesized) was not significant $(\beta=$ $.16, n s)$. The alternative model 1 with the controls also supported both Hypothesis 6 and Hypothesis 5, indicating no significant direct effects of empowering leadership $(\beta=-.05, n s)$ and need satisfaction $(\beta=.11, n s)$ on work-home enrichment, $\Delta \chi^{2}(2)=1.19, p=.55$. Alternative model 2 added a direct path from empowering leadership to work engagement to test the mediating role of needs satisfaction between them. Empowering leadership had a direct effect on work engagement however $(\beta=.49)$, and the model showed a statistically significant improvement in fit, $\Delta \chi^{2}(1)=31.22, p<.01$, which is inconsistent with Hypothesis 4 . Alternative model 2 with the controls also suggested the identical results; a direct path from empowering leadership to work engagement was significant $(\beta=.44, p<.01)$ along with the improvement in fit, $\Delta \chi^{2}(1)=29.41, p<.01$. 
Finally, mediation was tested with PROCESS model 6, which allows serial mediation analyses (Hayes, 2013); it simultaneously tested for mediation through needs satisfaction and work engagement independently, as well as for serial mediation through both variables. We ran separate bootstrapping analyses with 10,000 bootstrap samples; the predictor variable $(\mathrm{X})$ is modeled as influencing the criterion (Y) through four pathways. One pathway is indirect and runs from $\mathrm{X}$ to $\mathrm{Y}$ through the first mediator (M1) only; a second indirect pathway passes through both M1 and M2 sequentially, with M1 influencing M2; and a third indirect path runs through the second mediator (M2) only (see the right column named "path" in Table 3). A bias-corrected bootstrap 95\% CI for the product of these paths that does not include zero supports evidence of a significant indirect effect (Preacher \& Hayes, 2008). As shown in Table 3, bootstrapping results of the serial mediation analyses supported the indirect link of empowering leadership with workhome enrichment supporting Hypothesis 6 (i.e., the indirect path did not include zero, $a b=.03$, confidence interval [95\%]: lower limit $=.004$, upper limit $=.08, a b_{c s}=.02$; see the entries for the row labeled "Ind2" in Table 3). The completely standardized indirect effect size was .02, indicating that employees' work-home enrichment increases by .02 for every one standard deviation increase in empowering leadership indirectly through need satisfaction and work engagement. This means that the two mediators fully explained the effects of empowering leadership on work-home enrichment. However, it also shows a direct effect of empowering leadership on work engagement, which is consistent with the alternative model tests reported above (Table 3).

Regarding the study's overall hypothesized model as illustrated in Figure 1, there was good support in the data. In addition to the model fit statistics and the comparative fit statistics of alternative models, the bootstrapping results also supported the indirect effect of empowering 
WORK TO HOME EFFECT OF EMPOWERING LEADERSHIP 21

leadership on work-home enrichment via need satisfaction and work engagement. One caution, however, is that empowering leadership may have a direct effect (Alternative 2) as well as its indirect effect on work engagement. This suggests that work engagement may be a more important mediator in the model than need satisfaction is.

\section{Discussion}

Although a number of studies examined the potential effects of empowering leadership over the past decade, nonwork (e.g., home) consequences have been generally overlooked (see meta-analyses by Kim et al., 2018 and Lee et al., 2018). Using a four-wave design over a 9month period, the present study tested whether empowering leadership is related to subsequent work-to-home enrichment through its potential influence on the subordinates' innate psychological needs and work engagement. Results mostly supported the hypothesized serial mediation relationships. We found that empowering leadership may indeed be an important factor enabling work-home enrichment, but this effect is explained by mediators. Empowering leadership by itself may not be related to subsequent improvements in the quality of home life; it may be first necessary for it to satisfy subordinates' innate SDT needs, and especially to promote their work engagement, which can have a more direct effect on work-home enrichment.

Our results suggested that empowering leadership consists of behaviors that fulfill the theoretically innate psychological needs posed by self-determination theory, thus helping to illustrate a clear link between empowering leadership and SDT theories. We hypothesized this link because the theoretical construct of empowering leadership, with its emphasis on providing control and encouraging employees to take responsibility for their own work, is likely to be a close match for the set of SDT needs. The present study was the first to examine a link of empowering leadership with basic need satisfaction for subordinates, and it found strong and 
positive relationships between the two constructs $(r=.55$; Table 1$)$, suggesting that empowering leadership played an important role in creating environmental conditions required to fulfill employees' basic psychological needs, leading to work engagement and subsequently spilling over to the non-work domain.

Even though the overall model was supported, the findings also demonstrated that empowering leadership may more directly affect employees' work engagement rather than that link being entirely mediated by SDT's innate need satisfaction. According to the Job DemandsResources model (Bakker \& Demerouti, 2007), work engagement is a motivational process whereby adequate levels of job resources promote the channeling of energy into work tasks, leading employees to invest high levels of effort and have a strong involvement in their work. Empowering leadership can be a process of promoting this motivation in subordinates because it highlights joint decision making by leaders and their subordinates, or at least a shared influence on the decision-making process, a potential resource for employees to use in crafting their jobs (Kim \& Beehr, 2018, 2019). This can contribute to improving subordinates' motivation, because they are given opportunities to satisfy their higher order needs by engaging in participative goal setting and challenging work, such as identifying problems or planning the implementation of solutions. Therefore, empowering leadership may directly inspire work engagement in subordinates (e.g., Tuckey, Bakker, \& Dollard, 2012), rather than only through intrinsic need satisfaction as our original model proposed.

Additionally, the indirect effect of need satisfaction on work-home enrichment pointed to the importance of the second mediator, work engagement. Employees who have their SDT needs satisfied, that is they feel effective, confident, and connected to others and caring (or being cared for), are highly engaged in job activities; this engagement allows them to be better able to 
generate resources and to experience positive states, such as enjoyment, enthusiasm and happiness. Consequently, some of those resources and positive energy created by work may spillover to their home domain, helping facilitate their home role performance. Ultimately, these results of the work can enrich the employee's home life.

Overall, the present study suggests that empowering leaders' positive effects may reach beyond the workplace and help to foster employees' work-home enrichment. This reach occurs because the leaders empower the subordinates in ways that help them meet important intrinsic psychological needs, and thus become more engaged in job activities. These results shed light on the specific psychological mechanisms through which empowering leaders may influence their subordinates' home functioning: The study therefore expanded leadership and SDT research by showing that empowering leadership is a condition of the work environment that can satisfy important psychological need requirements outlined in SDT (e.g., Deci \& Ryan 2000). Furthermore, our findings provided the first empirical evidence that empowering leadership could have a spillover effect in the form of work-home enrichment; that is, there were effects of empowering leadership beyond the workplace, unlike most previous studies that focused only on organizational outcomes (Kim et al., 2018).

\section{Implications}

According to our findings, organizations may be able to help their employees experience enriching or positive spillover between work and private life domains. By encouraging leaders in influential positions to exhibit empowering behaviors with their subordinates, organizations may create environments where employees feel competence, relatedness, and autonomy, as well as stay engaged while at work. To actively promote this situation, it may be helpful to develop and offer leader training in the set of behaviors that are considered core characteristics of 
empowering leadership — encouraging subordinates in self-leadership and participation, conveying confidence in them, and granting them sufficient levels of autonomy or decision latitude (e.g., Amundsen \& Martinsen, 2014; Arnold et al., 2000; Kim \& Beehr, 2019). These empowering leadership behaviors likely boost employees' psychological need satisfaction and work engagement, which are considered favorable for organizations; in addition, however, these mediating variables can also lead employees to optimize their home roles, thus providing benefits to employees even when they are not in the workplace. Behavioral modeling via videotape and/or action training via role-plays could be useful tools for the development of empowering leadership behaviors (e.g., Frese, Beimel, \& Schoenborn, 2003; Manz \& Sims, 1986). Furthermore, in the selection process, organizations can select leaders who are already likely to perform empowering leadership roles through assessments in simulation exercises. Lastly, organizations can design and organize work interdependently, paying attention to autonomy levels, so that employees can be given sufficient opportunities to build relationships and learn from each other, which would be helpful for satisfying their psychological need for relatedness.

\section{Limitations and Future Research}

In spite of several contributions, the present study also had some limitations and directions for future research to improve or add to the present study. First, we used self-reported data that may raise concerns of common method effects. Using well-validated scales, especially when all of the variables in the model were measured at different points in time, helped to reduce those effects however (e.g., Podsakoff et al., 2012). In addition, the measurement model (overall confirmatory factor analyses) results suggested that all variables exhibited some discriminant validity and were empirically distinguishable, another indication that potential same-source bias 
was unlikely to be a serious problem. Nevertheless, it would be recommended to include other indicators of home performance (e.g., from family members) or manipulating empowering leadership (with experimental designs) in future research in order to further bolster the present study's findings. Second, potential boundary conditions, such as job and individual characteristics, types of work stressors, and cultural environments, could be considered in order to provide a fuller understanding of conditions when empowering leadership spills over to benefit the subordinates' home lives. Third, there are many other potential family outcomes, such as work-family balance and work-family conflict. Future research should consider examining the effects of empowering leadership on a broad range of employees' work-home outcomes in order to expand knowledge about the "reach" of this type of leadership. Fourth, our study excluded participants from outside the U.S. to control for a possible variety of social-cultural effects on workplace and home situations. Therefore, a cross-cultural study design is encouraged to offer the generalizability of our findings in the future research, or to find cross-cultural differences in leadership's spillover effects. Fifth, although the study measured variables at four points in time in the order in which each variable would occur based on the model, it would have been better to measure the variables at every time point, so that stabilities and changes of the variables could be taken into account. Future research could improve upon the present study.

Finally, future research might help us learn more about the process of empowering leadership predicting work-family enrichment by focusing on additional mediators. We were following a positive psychology approach in the present study, to explain good effects of work influencing family (enrichment). If we stay with this positivity, another "good" mediator variable might be organizational commitment, which could mediate between empowering leadership and work engagement. Prior research supports such a link, because a meta-analysis reported 
WORK TO HOME EFFECT OF EMPOWERING LEADERSHIP 26

empowering leadership to be positively related to commitment (Kim et al., 2018), and commitment is strongly related to job satisfaction (e.g., Caesens, Nguyen, \& Stinglhamber, 2018), although less is known about its relationship to the SDT need satisfaction in the model.

If we get away from a positive psychology approach, some "bad" variables might be able to mediate in the model. For example, workaholism might mediate between work engagement and work-family enrichment. Especially highly engaged employees could become so involved and dedicated to work that they give less time, resources, and attention to their family (Halbesleben, Harvey, \& Bolino, 2009), rather than engagement leading to work-family enrichment. That could happen if the work engagement is driven by malignant factors such as employers' excessive demands or employees' individual obsession such as workaholism. In the present study, we examined work engagement as it follows from more benign factors - the satisfaction of primary needs in SDT. Future research could examine alternative, less benign factors leading to engagement or engagement-mimicking responses. If workaholism were to mediate between engagement and work-family enrichment in the model, however, the relationship would not be simple, as there are multiple forms of workaholism, some related positively and some negatively to engagement (e.g., Mazzetti, Schaufeli, Guglielmi, \& Depolo, 2016; Schaufeli, 2016).

\section{Conclusions}

In sum, integrating the frameworks of empowering leadership and SDT, our study provided valuable insights for general employee well-being and effectiveness in their non-work as well as their work domains. Although family supportive programs help employees manage work and family (Butts, Casper, \& Yang, 2013), empowering behaviors of organizational leaders may also be predictive of how employees' work can enrich their home roles. Empowering 
WORK TO HOME EFFECT OF EMPOWERING LEADERSHIP 27

leadership fosters subordinates' feelings of worthiness, belongingness, and ability to control their environment, which may make them more engaged at work, but these positive work experiences eventually can contribute to enhanced work-home enrichment as well. We hope our study will inspire further research on empowering leadership and work-home interfaces in a variety of organizational and societal contexts. 
WORK TO HOME EFFECT OF EMPOWERING LEADERSHIP 28

\section{References}

Ahearne, M., Mathieu, J., \& Rapp, A. (2005). To empower or not to empower your sales force? An empirical examination of the influence of leadership empowerment behavior on customer satisfaction and performance. Journal of Applied Psychology, 90, 945-955.

Allen, T. D., \& Martin, A. (2017). The work-family interface: A retrospective look at 20 years of research in JOHP. Journal of Occupational Health Psychology, 22, 259-272.

Amundsen, S., \& Martinsen, Ø. L. (2014). Empowering leadership: Construct clarification, conceptualization, and validation of a new scale. The Leadership Quarterly, 25, 487-511.

Arnold, J. A., Arad, S., Rhoades, J. A., \& Drasgow, F. (2000). The empowering leadership questionnaire: The construction and validation of a new scale for measuring leader behaviors. Journal of Organizational Behavior, 21, 249-269.

Bakker, A. B., \& Demerouti, E. (2007). The job demands-resources model: State of the art. Journal of Managerial Psychology, 22, 309-328.

Braun, S., \& Nieberle, K. W. (2017). Authentic leadership extends beyond work: A multilevel model of work-family conflict and enrichment. The Leadership Quarterly, 28, 780-797.

Broeck, A., Vansteenkiste, M., Witte, H., Soenens, B., \& Lens, W. (2010). Capturing autonomy, competence, and relatedness at work: Construction and initial validation of the Workrelated Basic Need Satisfaction scale. Journal of Occupational and Organizational Psychology, 83, 981-1002.

Butts, M. M., Casper, W. J., \& Yang, T. S. (2013). How important are work-family support policies? A meta-analytic investigation of their effects on employee outcomes. Journal of Applied Psychology, 98, 1-25. 
Caesens, G., Nguyen, N., \& Stinglhamber, F. (2018). Abusive supervision and organizational dehumanization. Journal of Business and Psychology. 1-20.

Casler, K., Bickel, L., \& Hackett, E. (2013). Separate but equal? A comparison of participants and data gathered via Amazon's MTurk, social media, and face-to-face behavioral testing. Computers in Human Behavior, 29, 2156-2160.

Cheung, J. H., Burns, D. K., Sinclair, R. R., \& Sliter, M. (2017). Amazon Mechanical Turk in organizational psychology: An evaluation and practical recommendations. Journal of Business and Psychology, 32, 347-361.

Cho, E., \& Tay, L. (2016). Domain satisfaction as a mediator of the relationship between workfamily spillover and subjective well-being: A longitudinal study. Journal of Business and Psychology, 31, 445-457.

Deci, E. L., \& Ryan, R. M. (2000). The” what" and" why" of goal pursuits: Human needs and the self-determination of behavior. Psychological Inquiry, 11, 227-268.

Edwards, J. R., \& Rothbard, N. P. (2000). Mechanisms linking work and family: Clarifying the relationship between work and family constructs. Academy of Management Review, 25, 178-199.

Frese, M., Beimel, S., \& Schoenborn, S. (2003). Action training for charismatic leadership: Two evaluations of studies of a commercial training module on inspirational communication of a vision. Personnel Psychology, 56, 671-698.

Greenhaus, J. H., \& Powell, G. N. (2006). When work and family are allies: A theory of workfamily enrichment. Academy of Management Review, 31, 72-92. 
Greguras, G. J., \& Diefendorff, J.M. (2009). Different fits satisfy different needs: Linking person-environment fit to employee commitment and performance using selfdetermination theory. Journal of Applied Psychology, 94, 465-477.

Grzywacz, J. G., Almeida, D. M., \& McDonald, D. A. (2002). Work-family spillover and daily reports of work and family stress in the adult labor force. Family Relations: An Interdisciplinary Journal of Applied Family Studies, 51, 28-36.

Grzywacz, J. G., \& Marks, N. F. (2000). Reconceptualizing the work-family interface: An ecological perspective on the correlates of positive and negative spillover between work and family. Journal of Occupational Health Psychology, 5, 111-126.

Hackman, J. R., \& Oldham, G. R. (1980). Work redesign. Reading, MA: Addison-Wesley. Halbesleben, J. R., Harvey, J., \& Bolino, M. C. (2009). Too engaged? A conservation of resources view of the relationship between work engagement and work interference with family. Journal of Applied Psychology, 94, 1452-1465.

Hayes, A. F. (2013). Introduction to mediation, moderation, and conditional process analysis: A regression-based approach. New York: Guilford Press.

Huyghebaert, T., Gillet, N., Fernet, C., Lahiani, F., Chevalier, S., \& Fouqueraou, E. (2018). Investigating the longitudinal effects of surface acting on managers' functioning through psychological needs. Journal of Occupational Health Psychology, 23, 207-222.

Inceoglu, I., \& Fleck, S. (2010). Engagement as a motivational construct. In S. L. Albrecht (Ed.), New horizons in management. Handbook of employee engagement: Perspectives, issues, research and practice (p. 74-86). Edward Elgar Publishing.

Jöreskog, K. G., \& Sörbom, D. (2006). LISREL 8.8 [computer software]. Lincolnwood, IL: Scientific Software International. 
WORK TO HOME EFFECT OF EMPOWERING LEADERSHIP 31

Keith, M. G., Tay, L. \& Harms, P. D. (2017). Systems perspective of Amazon Mechanical Turk for organizational research: Review and recommendations. Frontiers in Psychology, 8, no pagination, retrieved online.

Kim, M., \& Beehr, T. A. (2018). Can empowering leaders affect subordinates' well-being and careers because they encourage subordinates' job crafting behaviors? Journal of Leadership \& Organizational Studies, 25, 184-196.

Kim, M., \& Beehr, T. A. (2019). The power of empowering leadership: Allowing and encouraging followers to take charge of their own jobs. International Journal of Human Resource Management. Advance online publication.

Kim, M., Beehr, T. A., \& Prewett, M. S. (2018). Employee responses to empowering leadership: A meta-analysis, Journal of Leadership \& Organizational Studies, 25, 257-276.

Lee, A., Willis, S., \& Tian, A. W. (2018). Empowering leadership: A meta-analytic examination of incremental contribution, mediation, and moderation. Journal of Organizational Behavior, 39, 306-325.

Lee, M. C. C., Idris, M. A., \& Delfabbro, P. H. (2017). The linkages between hierarchical culture and empowering leadership and their effects on employees' work engagement: Work meaningfulness as a mediator. International Journal of Stress Management, 24, 392-415.

Li, A., McCauley, K. D., \& Shaffer, J. A. (2017). The influence of leadership behavior on employee work-family outcomes: A review and research agenda. Human Resource Management Review, 27, 458-472.

Little, T. D., Rhemtulla, M., Gibson, K., \& Schoemann, A. M. (2013). Why the items versus parcels controversy needn't be one? Psychological Methods, 18, 285-300. 
Manz, C. C., \& Sims, H. P., Jr. (1986). Beyond imitation: Complex behavioral and affective linkages resulting from exposure to leadership training models. Journal of Applied Psychology, 71, 571-578.

Matthews, R. A., Wayne, J. H., \& Ford, M. T. (2014). A work-family conflict/subjective wellbeing process model: A test of competing theories of longitudinal effects. Journal of Applied Psychology, 99, 1173-1187.

Mazzetti, G., Schaufeli, W. B., Guglielmi, D., \& Depolo, M. (2016). Overwork climate scale: Psychometric properties and relationships with working hard. Journal of Managerial Psychology, 31, 880-896.

Park, J., Kim, J., Yoon, S., \& Joo, B. (2017). The effects of empowering leadership on psychological well-being and job engagement: The mediating role of psychological capital. Leadership \& Organization Development Journal, 38, 350-367.

Pearce, C. L., \& Sims, H. P. (2002). Vertical versus shared leadership as predictors of the effectiveness of change management teams: An examination of aversive, directive, transactional, transformational, and empowering leader behaviors. Group Dynamics: Theory, Research, and Practice, 6, 172-197.

Podsakoff, P. M., MacKenzie, S. P., \& Podsakoff, N. P. (2012). Sources of method bias in social science research and recommendations on how to control it. Annual Review of Psychology, 63, 539-569.

Preacher, K. J., \& Hayes, A. F. (2008). Asymptotic and resampling strategies for assessing and comparing indirect effects in multiple mediator models. Behavior Research Methods, 40, $879-891$. 
Rafaeli, A., \& Sutton, R. I. (1987). Expression of emotion as part of the work role. Academy of Management Review, 12, 23-37.

Ramsey, S. R., Thompson, K. L., McKenzie, M., \& Rosenbaum, A. (2016). Psychological research in the internet age: The quality of web-based data. Computers in Human Behavior, 58, 354-360.

Russo, M., Buonocore, F., Carmeli, A., \& Guo, L. (2018). When family supportive supervisors meet employees' need for caring: Implications for work-family enrichment and thriving. Journal of Management, 44, 1678-1702.

Ryan, R. M., \& Deci, E. L. (2000). Self-determination theory and the facilitation of intrinsic motivation, social development, and well-being. American Psychologist, 55, 68-78.

Schaufeli, W. B. (2016). Heavy work investment, personality and organizational climate. Journal of Managerial Psychology, 31, 1057-1073.

Schaufeli, W. B., Bakker, A. B., \& Salanova, M. (2006). The measurement of work engagement with a short questionnaire: A cross-national study. Educational and Psychological Measurement, 66, 701-716.

Schreurs, B., van Emmerik, I. J., Van den Broeck, A., \& Guenter, H. (2014). Work values and work engagement within teams: The mediating role of need satisfaction. Group Dynamics: Theory, Research, and Practice, 18, 267-281.

Tekleab, A., G., Sims, H. P. Jr., Yun, S., Tesluk, P. E., \& Cox, J. (2008). Are we on the same page? Effects of self-awareness of empowering leadership and transformational leadership. Journal of Leadership \& Organizational Studies, 14, 185-201.

ten Brummelhuis, L. L., \& Bakker, A. B. (2012). A resource perspective on the work-home interface: The work-home resources model. American Psychologist, 67, 545-556. 
WORK TO HOME EFFECT OF EMPOWERING LEADERSHIP 34

Tuckey, M. R., Bakker, A. B., \& Dollard, M. F. (2012). Empowering leaders optimize working conditions for engagement: A multilevel study. Journal of Occupational Health Psychology, 17, 15-27.

Van den Broeck, A., Vansteenkiste, M., De Witte, H., \& Lens, W. (2008). Explaining the relationships between job characteristics, burnout, and engagement: The role of basic psychological need satisfaction. Work \& Stress, 3, 277-294.

Van Wingerden, J., Bakker, A. B., \& Derks, D. (2017). Fostering employee well-being via a job crafting intervention. Journal of Vocational Behavior, 100, 164-174.

Walter, S. L., Seibert, S. E., Goering, D., \& O’Boyle, E. H. (2018). A tale of two sample sources: Do results from online panel data and conventional data converge? Journal of Business and Psychology, 1-28.

Watson, D., Clark, L. A., \& Tellegen, A. (1988). Development and validation of brief measures of positive and negative affect: The PANAS scales. Journal of Personality and Social Psychology, 54, 1063-1070.

Xanthopoulou, D., Bakker, A. B., Demerouti, E., \& Schaufeli, W. B. (2009). Reciprocal relationships between job resources, personal resources, and work engagement. Journal of Vocational Behavior, 74, 235-244.

Zhang, X., \& Bartol, K. M. (2010). Linking empowering leadership and employee creativity: The influence of psychological empowerment, intrinsic motivation, and creative process engagement. Academy of Management Journal, 53, 107-128.

Zhang, Y., Xu, S., Jin, J., \& Ford, M. T. (2018). The within and cross domain effects of workfamily enrichment: A meta-analysis. Journal of Vocational Behavior, 104, 210-227. 
Table 1

Means, Standard Deviations, Reliabilities, and Correlations

\begin{tabular}{|c|c|c|c|c|c|c|c|c|}
\hline Variables & Mean & $S D$ & $\alpha$ & 1 & 2 & 3 & 4 & 5 \\
\hline 1. Empowering Leadership (T1) & 3.83 & .68 & .91 & & & & & \\
\hline 2. SDT Needs Satisfaction (T2) & 3.94 & .59 & .90 & $.55^{* *}$ & & & & \\
\hline 3. Work Engagement (T3) & 4.76 & 1.22 & .95 & $.49^{* *}$ & $.37^{* *}$ & & & \\
\hline 4. Work-Home Enrichment (T4) & 3.30 & 1.02 & .91 & $.15^{*}$ & $.19^{* *}$ & $.27^{* *}$ & & \\
\hline 5. Negative Affectivity (T3) & 1.63 & .72 & .93 & $-.24^{* *}$ & $-.23^{* *}$ & $-.23^{* *}$ & -.00 & \\
\hline 6. Positive Affectivity (T3) & 3.53 & .86 & .93 & $.37^{* *}$ & $.48^{* *}$ & $.49^{* *}$ & $.26^{* *}$ & $-.20^{* *}$ \\
\hline
\end{tabular}

Notes. $N=289$. SDT $=$ Self-Determination Theory.

${ }^{*} p<.05$.

${ }^{* *} p<.01$. 
Table 2

Summary of Model Fit Indices

\begin{tabular}{|c|c|c|c|c|c|c|c|c|c|}
\hline Model Test & $\chi^{2}$ & $d f$ & CFI & IFI & NNFI & RMSEA & $\Delta \chi^{2}$ & $\Delta d f$ & $\Delta p$ \\
\hline \multicolumn{10}{|l|}{ Without Controls } \\
\hline Measurement Model & 125.36 & 71 & .99 & .99 & .98 & .05 & & & \\
\hline Hypothesized Model & 158.94 & 74 & .98 & .98 & .97 & .06 & & & \\
\hline Alternative Model 1 & 156.47 & 72 & .98 & .98 & .97 & .06 & 2.47 & 2 & .29 \\
\hline Alternative Model 2 & 127.72 & 73 & .99 & .99 & .98 & .05 & 31.22 & 1 & $<.01$ \\
\hline \multicolumn{10}{|l|}{ With Controls } \\
\hline Measurement Model & 268.49 & 155 & .98 & .98 & .98 & .05 & & & \\
\hline Hypothesized Model & 306.80 & 158 & .98 & .98 & .97 & .06 & & & \\
\hline Alternative Model 1 & 305.61 & 156 & .98 & .98 & .97 & .06 & 1.19 & 2 & .55 \\
\hline Alternative Model 2 & 277.39 & 157 & .98 & .98 & .98 & .05 & 29.41 & 1 & $<.01$ \\
\hline
\end{tabular}

Notes. $N=289 . \chi^{2}$-values for the structural models are significant at $p<.01 . \Delta \chi^{2}$ refers to comparisons with the hypothesized model. Controls = positive and negative affectivity. Alternative Model 1 added two direct paths from (1) empowering leadership to workhome enrichment and (2) needs satisfaction to work-home enrichment; Alternative Model 2 added a direct path from empowering leadership to work engagement. 
Table 3

Results of Bootstrapping 10,000 Samples for Estimating Indirect Effects of Empowering Leadership on Work-Home Enrichment through SDT Needs Satisfaction and Work Engagement

\begin{tabular}{|c|c|c|c|c|c|c|c|c|c|}
\hline \multirow[b]{2}{*}{$X$} & \multirow[b]{2}{*}{ M1 } & \multirow[b]{2}{*}{ M2 } & \multirow[b]{2}{*}{$\mathrm{Y}$} & \multirow{2}{*}{$\begin{array}{l}\text { Direct effect } \\
\qquad \beta(p)\end{array}$} & \multicolumn{5}{|c|}{ Indirect effects } \\
\hline & & & & & $a b$ & $S E$ & $C I_{95 \%}$ & $a b_{c s}$ & path \\
\hline \multirow{3}{*}{$\begin{array}{l}\text { Empowering } \\
\text { Leadership }\end{array}$} & \multirow{3}{*}{$\begin{array}{c}\text { SDT } \\
\text { Needs } \\
\text { Satisfaction }\end{array}$} & \multirow{3}{*}{$\begin{array}{c}\text { Work } \\
\text { Engagement }\end{array}$} & \multirow{3}{*}{ WHE } & \multirow{3}{*}{$-.06(.59)$} & .10 & .06 & $-.00^{\mathrm{a}}, .23$ & .07 & Ind1 \\
\hline & & & & & .03 & .02 & $.00^{\mathrm{b}}, .08$ & .02 & Ind2 \\
\hline & & & & & .15 & .05 & $.07,26$ & .10 & Ind3 \\
\hline
\end{tabular}

Notes. $N=289 . \mathrm{X}=$ a predictor; $\mathrm{M} 1$ and $\mathrm{M} 2=$ mediators; $\mathrm{Y}=$ an outcome. $\beta=$ direct effect. $a b=$ estimated indirect effect. $S E=$ bootstrap standard error. $a b, S E$, and $C I 95 \%$ were obtained from 10,000 bootstrap samples. $a b_{c s}=$ completely standardized indirect effect. $-.00^{\mathrm{a}}=-.008 ; .00^{\mathrm{b}}=004$. SDT $=$ Self Determination Theory. WHE $=$ Work-Home Enrichment. Ind $1=\mathrm{X} \rightarrow \mathrm{M} 1 \rightarrow \mathrm{Y}$; Ind2 $=\mathrm{X}$ $\rightarrow \mathrm{M} 1 \rightarrow \mathrm{M} 2 \rightarrow \mathrm{Y} ;$ Ind $3=\mathrm{X} \rightarrow \mathrm{M} 2 \rightarrow \mathrm{Y}$ 
Time $1 \stackrel{1 \text { month later }}{\longrightarrow}$ Time $2 \stackrel{1 \text { month later }}{\longrightarrow}$ Time $3 \stackrel{7 \text { months later }}{\longrightarrow}$ Time 4

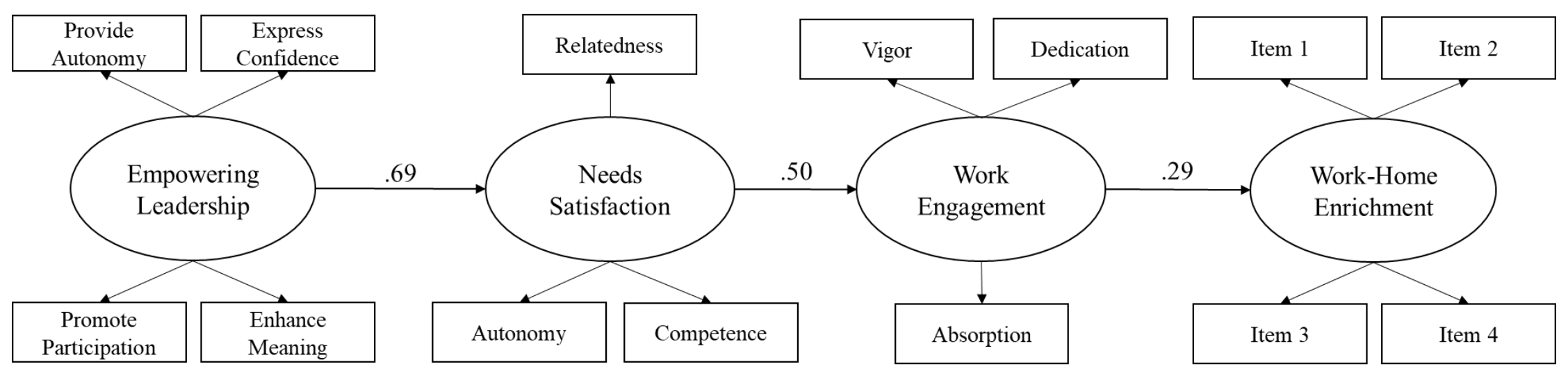

Figure 1. Hypothesized Model and Results 